\title{
Study on Ground Collapse of Covered Karst Soil Caves by Sudden Drop of Groundwater
}

\author{
Xuejun Chen, Ruijian Guo $(\mathbb{D}$, Lingming Tang, and Xiaochen Zhang \\ College of Earth Sciences, Guilin University of Technology, Guilin 541006, China \\ Correspondence should be addressed to Ruijian Guo; 361093737@qq.com
}

Received 20 June 2021; Accepted 27 July 2021; Published 11 August 2021

Academic Editor: Qibin Lin

Copyright (c) 2021 Xuejun Chen et al. This is an open access article distributed under the Creative Commons Attribution License, which permits unrestricted use, distribution, and reproduction in any medium, provided the original work is properly cited.

In this study, the ellipsoidal soil cave with vertical collapses in the covering karst area is studied. Based on certain assumptions, the mechanical model of karst collapse caused by groundwater drop was established. Then, based on the negative pressure calculation formula of soil cave cavity according to Boyle-Mariotte's law, the expression of the stability coefficient of the soil cave was proposed. Subsequently, the feasibility of the theoretical formula was verified. The calculation example analyzed the relationship of groundwater parameters and overburden thickness. The results show that when the initial groundwater level is higher than the top of cave, the law between the stability coefficient of soil cave and groundwater drawdown shows the jumping horizontal broken line. Thus, soil cave tends to collapse when the falling groundwater level drops over the vault; when the initial groundwater level ranges from the bottom to the top of the cave body, the stability coefficient and groundwater drawdown show a negative correlation law, the curve is steep at the early stage and then becomes gentle at the latter stage, and the higher the initial groundwater level in the cave is, the greater stability coefficient of soil cave reduces; when the initial groundwater level is lower than the bottom of the cave, the effect of drawdown is limited. In addition, for the small drawdown or low initial groundwater level, the stability coefficient of soil cave first decreases and then increases with the increases in thickness of overburden, and the thinner the overburden is, the greater the drawdown rate is; when the drawdown or the initial groundwater level is higher, the stability coefficient of soil cave positively relates to the thickness of the overburden layer.

\section{Introduction}

Sinkholes widely spread all over the world, especially in Florida [1-3], southwest China [4, 5], Jordan [6], Italy [7], Spain $[8,9]$, Iran $[10]$, and so on. The sinkhole collapse has caused devastating damage to buildings, roads, railways, and other facilities [11], leading to huge economic losses [2,12], and also threatening the safety of people's lives and properties. The development of sinkhole consists of two stages: internal collapse and surface collapse. The internal collapse is a slow process of soil failure, while the surface collapse is a sudden process of soil collapse caused by the expansion of soil holes [13]. The collapse is related to many factors such as weather, hydrology, geology, and human activities [14, 15]. When all the factors act together or one or two main factors act, the rapid development of internal collapse leads to the surface collapse. In a large number of cases, natural or human-induced hydrological changes can accelerate the development of subsidence. For example, the survey of Tazerbo wellfield in southeast Libya showed that sinkholes and subsidence resulted from groundwater withdrawal [16], and forty-one sinkholes collapsed in the southern suburbs of Liuzhou, Guangxi, China, in May 10, 2012; loss of soil particles due to heavy rainfall was responsible for the above phenomenon [17]. There are also other areas where heavy rainfall and flooding exacerbate the sinkhole collapse disaster [18]. Among many hydrological factors, the groundwater level change is the commonest cause of collapse [19-21].

Since the last century, many scholars have begun to study the theory of karst collapse and early warning. Pavlov, a Russian scholar, proposed the theory of "subsurface erosion" and stated that the decrease of underground water increased the hydraulic gradient; thus, the overburden soil was eroded 
and carried away by the water flow. Finally, the collapse of the roof was generated [22]. According to the "Vacuum Absorption Theory" proposed by Chinese scholar Xu Weiguo, in a certain scale of soil caverns, the rapid decline of the underground water level causes a "vacuum" between underground water surface and the floor of overburden, and the pressure difference between atmospheric and soil cavern acts on the soil of overburden, leading to the collapse of soil cavern.

Romanova and Kaufmanna [23] believed that dissolution is the main factor in the development stage of sinkhole, and the final collapse is sensitive to the change of hydraulic conductivity and hydraulic gradient. Wang and He [24] think that critical soil cavern is the final stage of the soil tunnel development and obtained its limit equilibrium height of the overburden layer. Chang and Zhang [25] conducted an experimental study on soil particle loss caused by hydraulic erosion under complex stress conditions and defined three critical hydraulic gradients. Based on Terzaghi's assumption and excess pore water pressure theory, Long and Lujuan [4] proposed the groundwater level critical value for the formation, evolution, and roof collapse of the soil cavern, which can be used for the precaution of surface collapse sinkholes. Nam et al. [26] studied sinkholes in Florida and identified the main causes of sinkholes, including water head difference, soil permeability, cover layer thickness, and aquifer system thickness. They used regression analysis to quantify the influence of these factors on sinkhole formation. Xiao [27] studied the effects of water-gas mutual drive, negative pressure action, negative pressure suction, and submersible erosion caused by the change of the groundwater level, as well as the influence of these effects on the stability of the sinkhole, and obtained the mathematical expression of the karst collapse factor.

The study and early warning of karst collapse can be based on the actual site investigation or the theoretical study of the mathematical and physical calculation model. In terms of theoretical research, for the establishment of physical models in karst stability analysis, most soil holes are of simple three-dimensional shapes (spherical and cylindrical), or the models are simplified into plane problems directly. As for the study of the space shape of underground cavern, most scholars focused on the stress of the points around the caverns for various stress states. Edwards [28] obtained four parts of the stress solution of the ellipsoidal void in the infinite universe for five stress states. Using the principle of superposition, under triaxial stress, Liao [29] obtained the extreme stress solution of the key point on the ellipsoidal cavity wall and evaluated the stability of the cavity. Using the function of the complex variable method, Li et al. [30] obtained the exact answer about the soil stress field of the elliptical cavity and analyzed the influence of the shape of the cavity and the external load on the plastic zone. For the rectangular karst cave, Zhao et al. [31] calculated the stratum stress under load, the maximum and minimum principal stress of any section, and evaluated the stability of the karst cave.

Previous studies have contributed to understanding the mechanism of karst caves. However, the influence of hydrodynamic conditions and three-dimensional shape of the soil cave on the stability of the covering layer is ignored. To study the spatial effect of soil cavity in the process of groundwater level change and to analyze the influence of hydrodynamic conditions on the stability of soil cavity, the soil cavern model is set as a common ellipsoid. The surface soil of the Quaternary strata is dense. In the process of groundwater downfall, the atmosphere cannot seepage to the hole space in time; therefore, the main collapsing force at this time is the negative pressure. The research focused on analyzing the relationship between negative pressure and groundwater level parameters and the space effect of the cave and getting the analytical expression of the soil hole stability coefficient. Then, the internal relationships among the initial groundwater level, the drawdown, and the overburden thickness under the shape effect of the spatial cavern are further analyzed.

\section{Theoretical Analysis of Soil Cave Collapse Caused by Groundwater Drop}

2.1. Basic Assumptions. The study analyzed the collapse mechanism of covered karst soil caves based on the following assumptions.

(1) The research object is the ellipsoidal soil cave with straight tube collapse; thus, the shear plane extends vertically from the arch foot to the surface.

(2) The surface soil is dense and its porosity is small; therefore, under the condition of groundwater sudden drop, it blocks the seepage of air into the soil hole in short time. The mole number of air in the cave remains unchanged, and the cavity pressure conforms to Boyle-Mariotte's law.

(3) The difference between saturated bulk density and natural bulk density is small; thus, the influence of groundwater drop on soil bulk density is negligible. In addition, due to the short interval between groundwater descent and collapse, groundwater seepage and softening of soil strength are not considered.

2.2. Mechanical Model. The overburden soil above the soil cave is selected for the force analysis (Figure 1). Basic parameters include the soil gravity $(G=S H \gamma-(2 / 3) \pi a b c \gamma)$, negative pressure caused by drawdown of groundwater $(F=\Delta P S)$, shear strength at any point on the side of failure body $\left(\tau=C+K_{0} \gamma z \tan \phi\right)$, and the side friction of the failure body $\left(f=\int_{0}^{H} \tau D \mathrm{~d} z=(1 / 2) K_{0} \gamma D H^{2} \tan \phi+D C H\right)$. The stability coefficient of overburden soil is

$$
K=\frac{f}{G+F}=\frac{(1 / 2) K_{0} \gamma H^{2} \tan \phi+C H}{\gamma H+\Delta P-(2 / 3) c \gamma} \frac{D}{S},
$$

where $\gamma$ is the natural bulk density of overburden (the multilayer soil is weighted average), $z$ represents the depth of a particle, $H$ is the thickness of overburden soil (the distance from arch foot to ground), $C, \phi$ are the cohesion and internal 

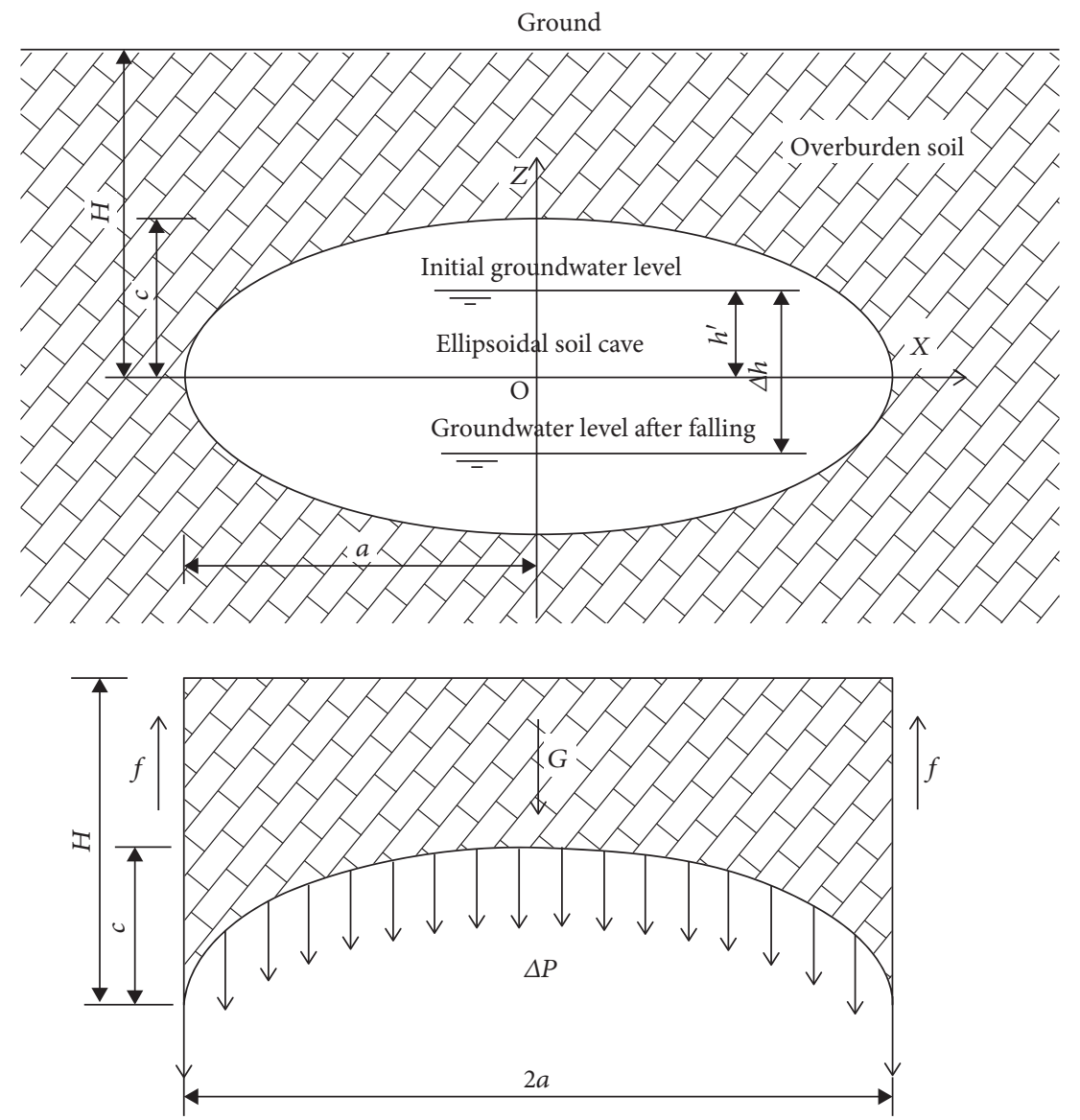

Figure 1: Mechanical model of soil cave collapse induced by groundwater drop.

friction angle of the soil (the multilayer soil is weighted average), $K_{0}$ is the soil lateral pressure coefficient (under the condition of sudden drop of groundwater, coefficient of earth pressure at rest can be taken), and $\Delta P$ is the negative pressure stress caused by groundwater drop. Because of the projection of the outermost edge of ellipsoidal soil hole on the horizontal plane is an ellipse, $a, b$ are the major and minor axes of the ellipse, $c$ is the height of the ellipsoid, and $S$ and $D$ are the area and perimeter of the ellipse, respectively; then, $S=\pi a b, D=2 \pi b+4(a-b)$.

2.3. Calculation of Cavity Negative Pressure Stress $\Delta P$. According to formula (1), there is a negative correlation between the collapse stability coefficient $K$ and the cavity negative pressure stress $\Delta P$. Thus, $\Delta P$ is an important inducement for the collapse of soil cave. According to Boyle-Mariotte's law, $\Delta P$ relates to the change of cavity volume. It strongly relates to the initial groundwater level $h^{\prime}$, drawdown $\Delta h$, shape, and size of the cavern. Now, classify it in terms of position $h^{\prime}$.

2.3.1. The Initial Groundwater Level Is above the Vault of the Cave $\left(h^{\prime}>c\right)$. According to the groundwater level in the soil hole after falling, it can be divided into two situations.

When the groundwater level after dropping is still in the overburden soil $\left(h^{\prime}-\Delta h>c\right)$, the soil hole is still filled by groundwater; then, the hole negative pressure stress $\Delta P$ is equal to 0 .

When the groundwater level after dropping is in the soil hole $\left(-c<h^{\prime}-\Delta h<c\right)$ or below the soil hole bottom $\left(h^{\prime}-\Delta h<-c\right)$, the cavity above the groundwater table is vacuumed; then, $\Delta P$ is equal to $1 \mathrm{~atm}$.

2.3.2. The Initial Groundwater Level Is in the Hole $\left(-c<h^{\prime}<c\right)$. Taking the center of the ellipsoid soil cave as the origin, the coordinate system is established, if the plane equation of the groundwater level is $z=h^{\prime}$, the crosssectional area of ellipsoid, cut by the plane, is $S^{\prime}=\left(\pi a b\left(c^{2}-h^{\prime 2}\right) / c^{2}\right)$, and the volume of cavity above the plane is $V=\int_{h}^{c}\left(\pi a b\left(c^{2}-z^{2}\right) / c^{2}\right) \mathrm{d} z=\pi a b\left((2 / 3) c-h^{\prime}+\right.$ $\left.\left(h^{\prime 3} / 3 c^{2}\right)\right)$.

According to Boyle-Mariotte's law, there is $P_{\alpha} V_{1}=P_{1} V_{2}$, where $V_{1}$ and $V_{2}$ represent the volume of the cavity above the plane before and after the drawdown of groundwater, respectively. $P_{1}$ represents the air pressure in the cavity after the drawdown of groundwater. $P_{\alpha}$ is equal to $1 \mathrm{~atm}$; then, the hole negative pressure stress $\Delta P=P_{\alpha}-P_{1}=$ $\left(1-\left(V_{1} / V_{2}\right)\right) P_{\alpha}$.

According to the groundwater level in the soil hole after it has fallen, it also can be divided into two situations.

When it is in the soil hole $\left(-c<h^{\prime}-\Delta h<c\right)$, after derivation, $\Delta P$ is 


$$
\Delta P=\frac{\Delta h+\left(\left(h^{\prime}-\Delta h\right)^{3}-h^{\prime 3} / 3 c^{2}\right)}{(2 / 3) c-h^{\prime}+\Delta h+\left(\left(h^{\prime}-\Delta h\right)^{3} / 3 c^{2}\right)} P_{\alpha} .
$$

When it is below the bottom of the soil hole $\left(h^{\prime}-\Delta h<-c\right), \Delta P$ is

$$
\Delta P=\left(\frac{1}{2}+\frac{3 h^{\prime}}{4 c}-\frac{h^{\prime 3}}{4 c^{3}}\right) P_{\alpha} .
$$

\subsubsection{The Initial Groundwater Level Is below the Bottom of} the Soil Hole. Underground water is absent in the soil hole body, and the volume of air does not change; then, $\Delta P$ is equal to 0 .

2.4. Theoretical Comparison. If the research object in this study is degenerated into cylindrical covering layer, $a$ is equal to $b$ and $r$ and $c$ is equal to 0 . Equation (1) yields that $K=\left(K_{0} \gamma H^{2} \tan \phi+2 \mathrm{CH} / r(\gamma H+\Delta P)\right)$. This formula is consistent with reference [28], which shows the accuracy of the abovementioned theoretical formula of collapse. The difference is the acquisition of the negative pressure stress. In reference [28], it can be measured by experiment, but the operation is difficult and timeconsuming. In this study, the theoretical formula of negative pressure stress is established based on Boyle-Mariotte's law, which is faster and more convenient. At the same time, this study is not only applicable to the analysis of the collapse caused by groundwater drop in the overburden of ellipsoid and cylinder but also for the overburden of sphere and other domes, which greatly expands the scope of application and is closer to the engineering practice.

\section{Case Study}

The collapse of a soil cave caused by groundwater pumping is located in Datansha Island, Guangzhou, China. The study site comprised of the Quaternary sediments with a thickness of 17.8-28.7 m, consisting of Holocene deposits $Q^{\mathrm{ml}}$, alluvial silt $Q_{1}^{\mathrm{al}}$, and sand $Q_{2}^{\mathrm{al}}$ and residual deposit loam and clay $Q^{\mathrm{el}}$. Ellipsoid hole T9 was chosen as the research object because its upper soil was relatively dense and close to monitoring well A2. The length and short axis of T9 were $15 \mathrm{~m}$ and $10 \mathrm{~m}$, respectively; thus, $a=7.5 \mathrm{~m}, b=5 \mathrm{~m}, c=5 \mathrm{~m}$. According to the field investigation, T9 collapsed on 27th January due to the rapid pumping of groundwater, and the groundwater level of the well A2 dropped to $1.88 \mathrm{~m}$, about $2.2 \mathrm{~m}$ lower than the normal water level. Then, $h^{\prime}=2.58 \mathrm{~m}, \Delta h=2.2 \mathrm{~m}$. According to the geological profile of A2, the geological profile is as shown in Figure 2. The strata parameters are listed in Table 1 . The corresponding average values are $\phi=12.5^{\circ}, C=20.4 \mathrm{kPa}, \gamma=17.4 \mathrm{kN} / \mathrm{m}^{3}$.

The data are from the geological hazards investigation report in Datansha Isl and in Guangzhou city [32].
The stability coefficient of the soil hole is 1.1 before the pumping by calculating. Although the overburden layer is relatively thin, the soil hole is still stable, which is consistent with the following conclusion. Because the overburden is almost dense soil and the collapse occurs within a short period of time after water pumping, negative pressure can be considered as the main controlling factor for the collapse of the soil tunnel. Therefore, the substitution of the above parameters into equation (2) yields $\Delta P=67.42 \mathrm{kPa}$. Since the initial water level is in the upper half of the soil cave, the groundwater level sudden drops, resulting in a large negative pressure in the soil cave, and the stability coefficient of the soil cave drops to 0.5 , causing the collapse of the soil cave. This phenomenon is consistent with the conclusion in this study.

\section{Example Analysis}

On the basis of the theoretical study, we are trying to analyze the influence of groundwater parameters $\left(h^{\prime}, \Delta h\right)$ and overburden thickness $(H)$ on the stability of soil cave. The mechanical parameters are $\gamma=19 \mathrm{kN} / \mathrm{m}^{3}, C=20 \mathrm{kPa}, \phi=17^{\circ}, K_{0}=0.5$ and the shape parameters are $a=4 \mathrm{~m}, b=3 \mathrm{~m}, c=3 \mathrm{~m}$.

4.1. Influence of Groundwater Parameters. When $H=11 \mathrm{~m}$, the influence of the initial groundwater level and groundwater drawdown on the stability coefficient $K$ is analyzed. In Figure $3, K$ is the ordinate and the relative drawdown $\left(\Delta h / h^{\prime}+c\right)$ is the abscissa.

Generally, the influence of groundwater parameters can be divided into three categories.

In the first type, $h^{\prime}>3 \mathrm{~m}$, the initial groundwater level is above the vault, as shown by $h^{\prime}=4 \mathrm{~m}$ in Figure 3(a); when $\Delta h<1 \mathrm{~m}$, the stable groundwater level is still above the vault, and negative pressure is absent when the groundwater drops. At this time, $\Delta P=0$, the stability coefficient is the maximum with a value of 1.401; when $\Delta h<1 \mathrm{~m}$, the groundwater falls into the soil hole or below the cave bottom, resulting in cavity vacuum, and the stability coefficient is the minimum with a value of 0.88 . They are shown as two segment jump horizontal lines, being parallel to the abscissa, and the jumping point is $\left(\Delta h / h^{\prime}+c\right)=0.143$. In this case, the stability coefficient of overburden changes from the maximum to the minimum. Therefore, when the initial groundwater level is above the vault and the falling groundwater level is just below the vault, it is very easy to cause the instantaneous collapse of the covering layer.

In the second type, when $h^{\prime}<-3 \mathrm{~m}$, the initial groundwater level is below the bottom of the soil hole, as shown by the case of $h^{\prime}=-3.5 \mathrm{~m}$ in Figure 3(a). At this time, the decline of groundwater will not lead to vacuum negative pressure and will not lead to collapse. Thus, the stability coefficient is the maximum with a value of 1.401, shown as a horizontal line with negative abscissa in the figure. Therefore, when the actual initial groundwater level is very low and is lower than the hole, the decline of groundwater hardly affects the stability of the soil hole and will not cause immediate collapse. 


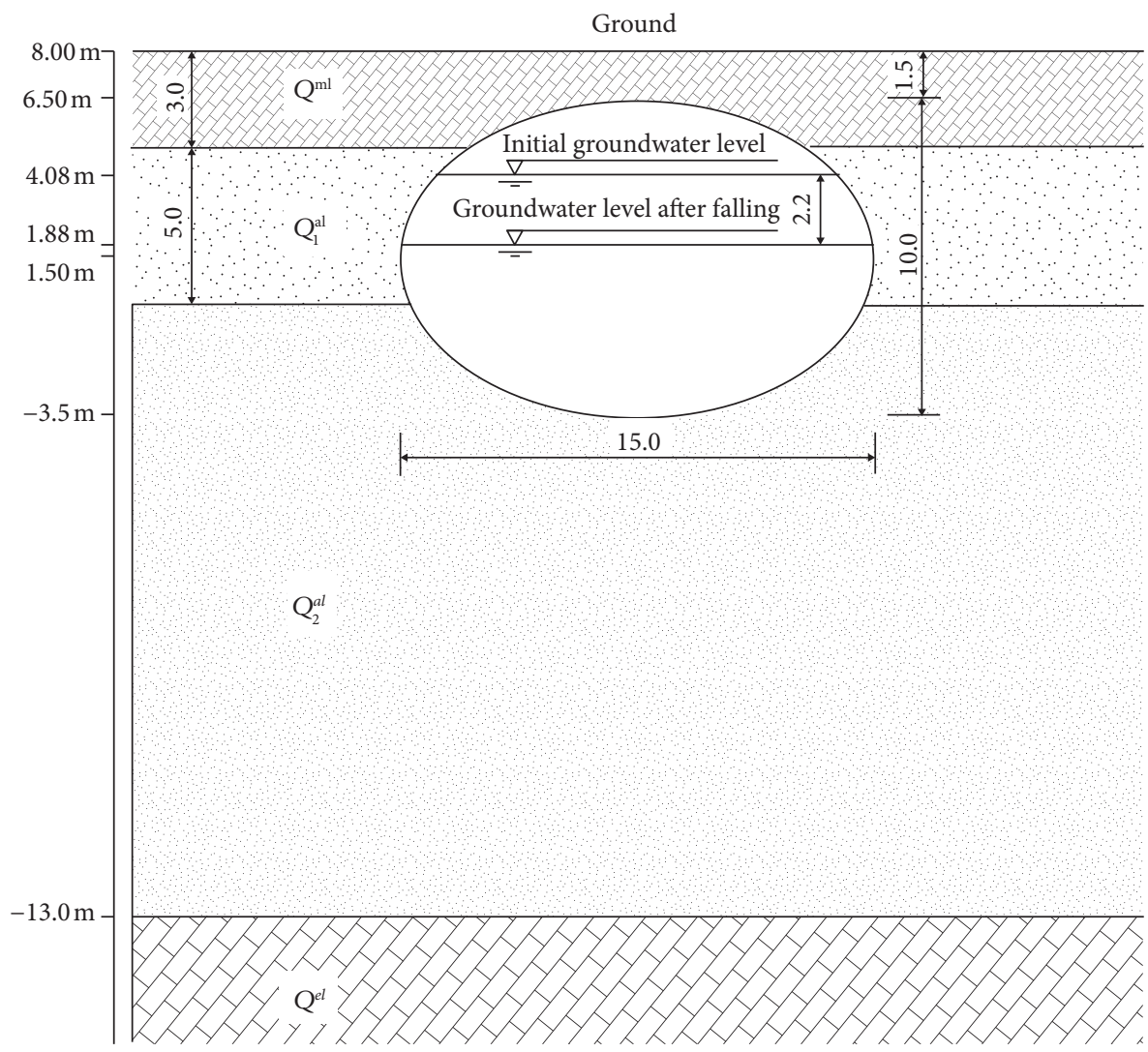

FIgURE 2: Geological profile of A2 (unit, m).

TABLE 1: Quaternary strata parameters.

\begin{tabular}{lccc}
\hline Strata & $\gamma\left(\mathrm{kN} / \mathrm{m}^{3}\right)$ & $C(\mathrm{kPa})$ & $\phi\left({ }^{\circ}\right)$ \\
\hline$Q^{\mathrm{ml}}$ & $18-20$ & $32-40$ & $12-18$ \\
$Q_{1}^{\text {al }}$ & $15-18$ & $5-9$ & $4-10$ \\
$Q_{2}^{\text {al }}$ & $17-23$ & $6-12$ & $12-15$ \\
$Q^{\text {el }}$ & $18-20$ & $35-46$ & $18-25$ \\
\hline
\end{tabular}

In the third type, when $-3<h^{\prime}<3 \mathrm{~m}$, the initial groundwater level is in the hole, eleven cases from $h^{\prime}=2.5 \mathrm{~m}$ to $h^{\prime}=-2.5 \mathrm{~m}$ are, respectively, considered as shown in Figure 3(b), and the following two laws can be obtained.

4.1.1. The Effect of Relative Drawdown on K. For the same initial groundwater level, $K$ decreases with the increase of relative drawdown of groundwater. In other words, the greater the groundwater drop, the more unstable the overburden is. However, with the increase of drawdown, the decline rate of $K$ gradually decreases. Therefore, the curves in Figure 3(b) are basically steep at the early stage and gentle at the later stage. For $h^{\prime}=2.5 \mathrm{~m}$, when the groundwater level drops by the first $0.25 \mathrm{~m}, K$ rapidly drops from 1.401 to 1.063 , resulting in a reduction ratio of $33.8 \%$. When the groundwater level drops by the second $0.25 \mathrm{~m}, K$ decreases from 1.063 to 0.979 with a reduction ratio of $8.4 \%$. When the groundwater level drops for the sixth $0.25 \mathrm{~m}, K$ decreases from 0.908 to 0.903 with a small reduction ratio of $0.5 \%$. It can be seen that the reduction of $K$ decreases with the increase of drawdown, which indicates that the sensitivity of $K$ to $\left(\Delta h / h^{\prime}+c\right)$ decreases at the same initial water level. Therefore, it can be seen from Figure 3(b) that when $\left(\Delta h / h^{\prime}+c\right)$ is large, the curve becomes more gentle and finally tends to be a stable value. This indicates that at the early stage of water level decline, overburden is more prone to instability, while in the middle and late stages, overburden stability slightly changes.

\subsubsection{The Influence of Initial Groundwater Level on $K$}

(a) At the initial stage of groundwater decline, the higher initial groundwater level results in greater $K$ decreases (Figure 3(b)). The larger $h^{\prime}$ is, the steeper the front section of the curve is. With the decrease of $h^{\prime}$, the front part of the curve becomes gentler. Therefore, $K$ is more sensitive to high initial groundwater levels. For example, when $h^{\prime}=2.5 \mathrm{~m}$ and $h^{\prime}=2 \mathrm{~m}, K$ are 1.063 and 1.169 when the water level drops $0.25 \mathrm{~m}$, respectively. The difference is 0.106 . When $h^{\prime}=-1 \mathrm{~m}$ and $h^{\prime}=-1.5 \mathrm{~m}$, the corresponding $K$ are 1.349 and 1.363 . The difference is 0.014 . It indicates that when the initial groundwater level is high, a small drop will lead to great difference in stability coefficient; otherwise, the difference is small.

(b) The latter section of each curve is gentle and finally tends to be a constant. At large drawdown, $K$ is more sensitive to the differences between low initial 


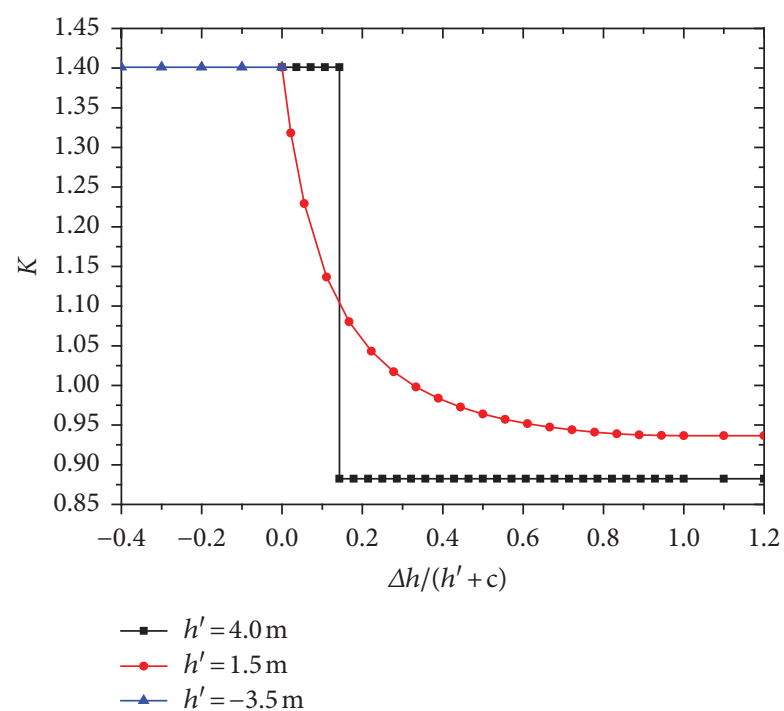

(a)

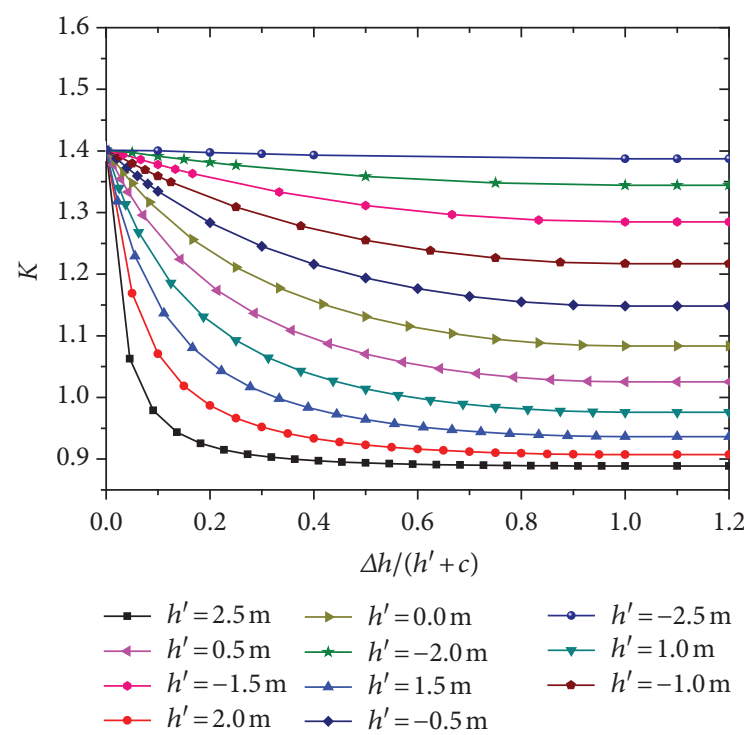

(b)

FIgURE 3: The effect of groundwater parameters $h^{\prime}$ and $\Delta h$.

groundwater levels. Therefore, in the picture, the relative distance between the gentle section of each curve increases from the bottom to the top. For example, when $h^{\prime}=2.5 \mathrm{~m}$ and $h^{\prime}=2 \mathrm{~m}, K$ decreases to the minimum when the groundwater drops to the bottom of the hole, with two values of 0.889 and 0.907 , respectively. The difference is 0.018 . While $h^{\prime}=-1 \mathrm{~m}$ and $h^{\prime}=-1.5 \mathrm{~m}$, the corresponding values are 1.217 and 1.285 with a difference of 0.068 . Thus, when the groundwater drop is large, the difference of $K$ between high initial groundwater levels is small, and the difference between low initial groundwater levels is large.

The above analysis shows that when the initial groundwater level is in the soil hole, the safety of the initial drawdown of groundwater needs to be studied to avoid accidents caused by the large reduction of $K$. Especially, when the initial groundwater level in the hole is high, even if the drawdown is very small, we should pay attention to the sudden change of overburden stability and take preventive measures. In addition, we can predict $K$ of the two cases of small drawdown in the low groundwater level and large drawdown in the high groundwater level using empirical analogy.

4.2. The Influence Analysis of Overburden Thickness. The influencing of overburden thickness was investigated when the other parameters are constants. First, when the groundwater level is stable, the values of $K$ under different overburden thickness and groundwater descent depth were calculated. Second, for the same groundwater depth reduction, the values of $K$ for different overburden thickness and initial water level were computed.

In Figure 4, taking different initial water levels $h^{\prime}=2.5 \mathrm{~m}, 1.0 \mathrm{~m},-0.5 \mathrm{~m},-1.5 \mathrm{~m}$ as examples, the curves under different overburden thicknesses were obtained. We found the following laws:

(1) It is worth noting that when the groundwater level is constant, $K$ decreases rapidly first and then increases slowly with the increase in overburden thickness. The cutoff point is $H=7 \mathrm{~m}$, when $H=4 \mathrm{~m}, 5 \mathrm{~m}, 6 \mathrm{~m}$, $7 \mathrm{~m}, 8 \mathrm{~m}, 9 \mathrm{~m}, 10 \mathrm{~m}$, and the values of $K$ are 1.647 , $1.450,1.374,1.348,1.345,1.360$, and 1.366 , respectively. The above phenomena result from the different effects of thickness on resistance and collapse force. Therefore, in the absence of groundwater and external load, if the overburden soil cohesion and integrity are high, the soil hole has good self-stability, although the overburden is very thin.

(2) As mentioned in 4.1, the curve of $K$ 's variation with $\left(\Delta h / h^{\prime}+c\right)$ can be divided into steep section and gentle sections. The initial drawdown of groundwater corresponds to the steep section of the curve, which is closely related to the thickness of overburden, the thinner the overburden is, the greater the decrease of $K$ is. Figure 4(a) shows that when $H=$ $4 \mathrm{~m}$ and $h^{\prime}=2.5 \mathrm{~m},\left(\Delta h / h^{\prime}+c\right)$ changes from 0 to 0.05 . Correspondingly, $K$ decreases rapidly from 1.647 to 0.675 , with a decrease value of 0.972 . When $H=7 \mathrm{~m}$ and $h^{\prime}=2.5 \mathrm{~m}, K$ decreases from 1.348 to 0.699 , with a decrease value of 0.649 . Thus, the smaller $H$ leads to the greater variation of $K$ for the same relative drawdown. 


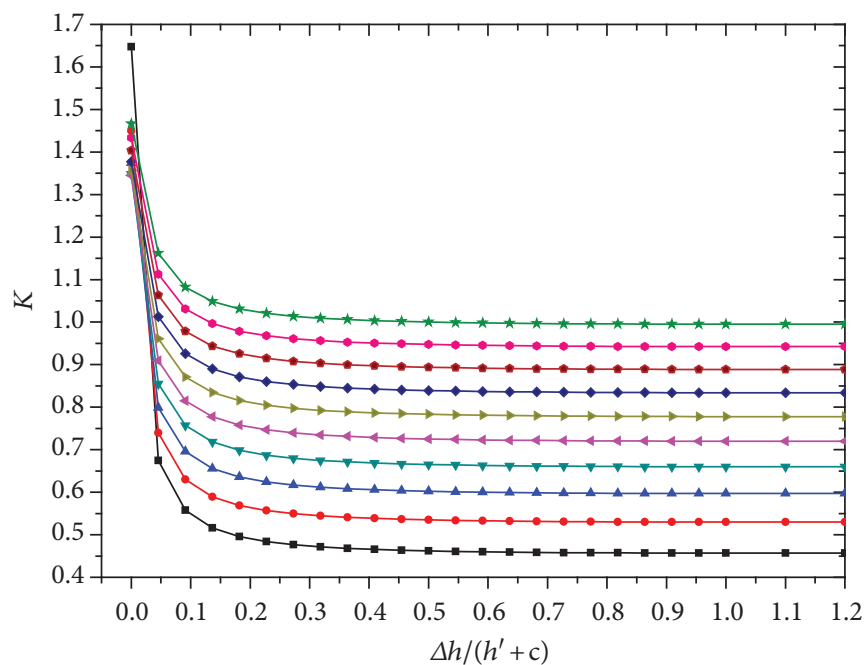

$\rightarrow H=4 \mathrm{~m} \longrightarrow H=6 \mathrm{~m} \longrightarrow H=8 \mathrm{~m}$

$\rightarrow H=9 \mathrm{~m} \quad \rightarrow H=11 \mathrm{~m} \quad \nVdash H=13 \mathrm{~m}$

$\rightarrow H=5 \mathrm{~m} \quad \rightarrow H=7 \mathrm{~m}$

$\rightarrow H=10 \mathrm{~m} \quad \longrightarrow H=12 \mathrm{~m}$

(a)

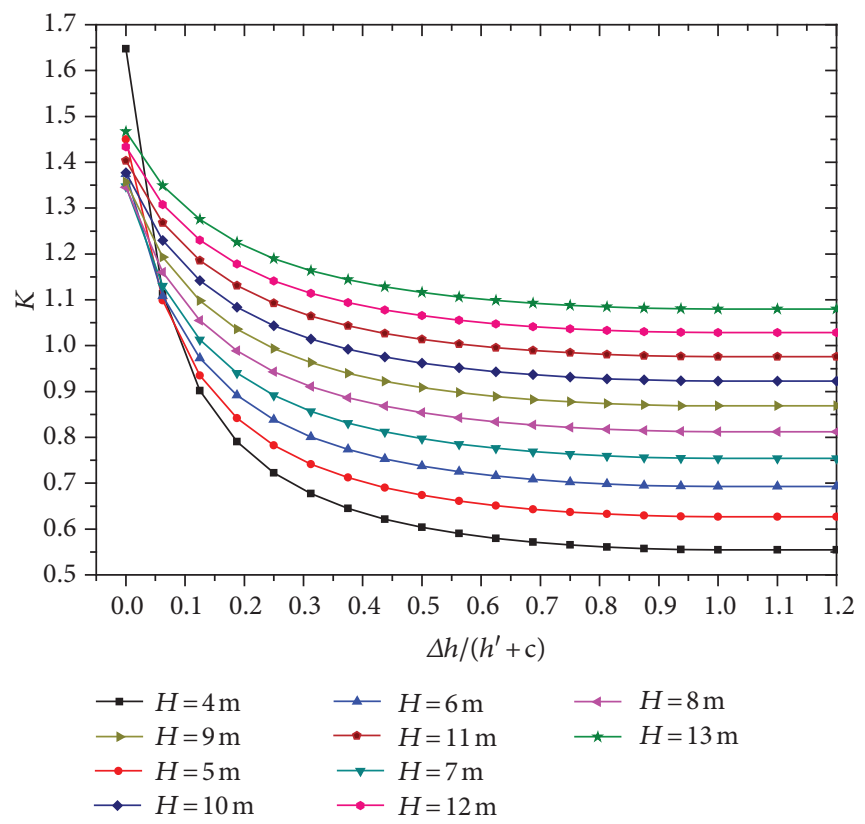

(b)

Figure 4: Continued. 


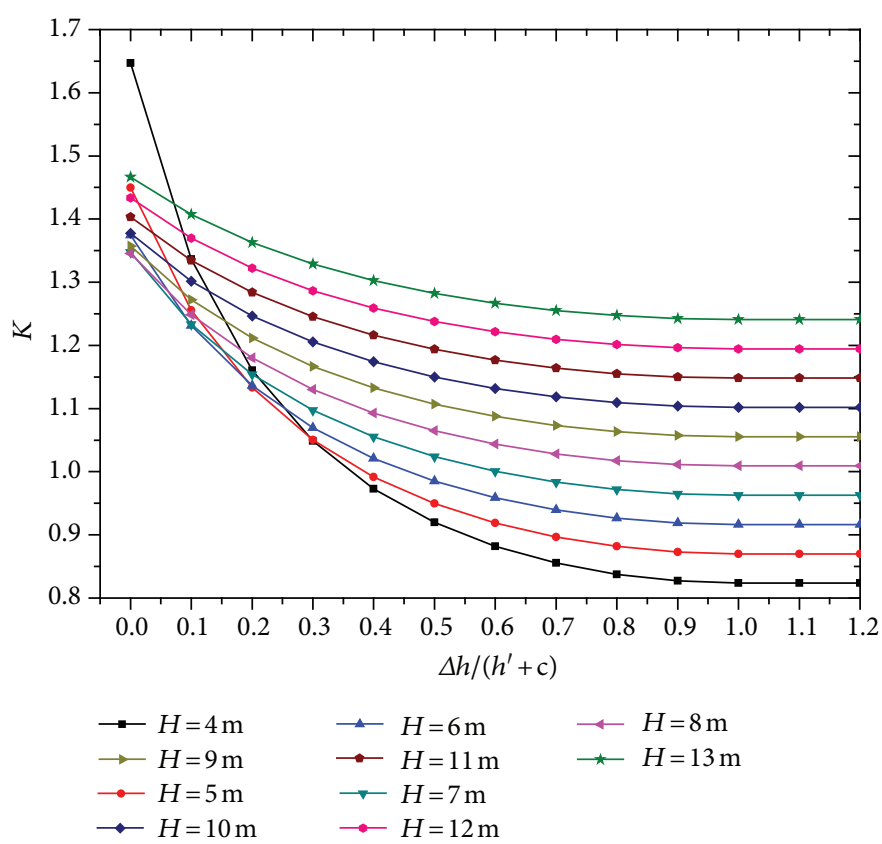

(c)

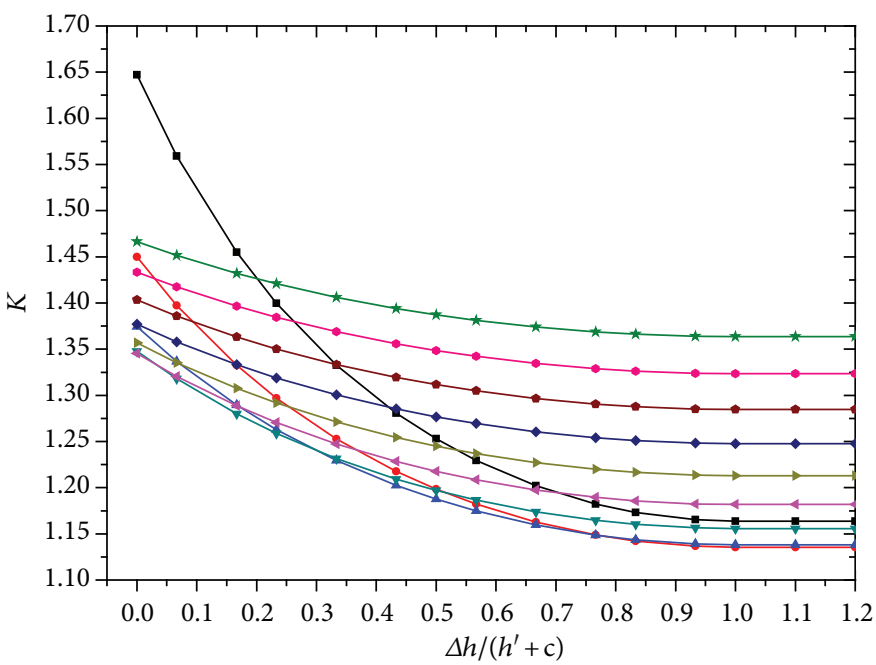

$\begin{array}{ll}\rightarrow H=4 \mathrm{~m} & \rightarrow H=6 \mathrm{~m} \\ \rightarrow H=9 \mathrm{~m} & \rightarrow H=11 \mathrm{~m}=8 \mathrm{~m} \\ \rightarrow H=5 \mathrm{~m} & \rightarrow H=7 \mathrm{~m} \\ \rightarrow H=10 \mathrm{~m} & \rightarrow H=13 \mathrm{~m}\end{array}$

(d)

FIGURE 4: Influence of overburden thickness under the same initial groundwater level. (a) $h^{\prime}=2.5 \mathrm{~m}$. (b) $h^{\prime}=1.0 \mathrm{~m}$. (c) $h^{\prime}=-0.5 \mathrm{~m}$. (d) $h^{\prime}=-1.5 \mathrm{~m}$.

Figure 5 shows the drawdown are $\Delta h=0.5 \mathrm{~m}, 1 \mathrm{~m}$, $2.5 \mathrm{~m}, 4 \mathrm{~m}$, respectively. First, the change trend of four charts is basically the same. The curves for $h^{\prime}=4 \mathrm{~m}$ and $h^{\prime}=-3 \mathrm{~m}$ in Figures 5(a)-5(b) coincide because the drawdown does not produce negative pressure. Thus, the stability coefficient $K$ is the same and the maximum. In Figures $5(\mathrm{c})-5(\mathrm{~d}), K$ is the smallest when $h^{\prime}=3 \mathrm{~m}$ because an standard atmospheric pressure is generated in the soil cavity. In addition, the other conclusions are as follows:
(1) The highest and lowest curves of each graph curve are fixed, which are $h^{\prime}=-3 \mathrm{~m}$ and $h^{\prime}=3 \mathrm{~m}$, respectively. The other curves locate between the two curves. The final shape of the enclosed area is large on the left side and small on the right side. In other words, for the same drawdown, when the overburden is thinner, $K$ is more sensitive to $h^{\prime}$, and when the overburden is thicker, the variation of $K$ with $h^{\prime}$ becomes smaller. 


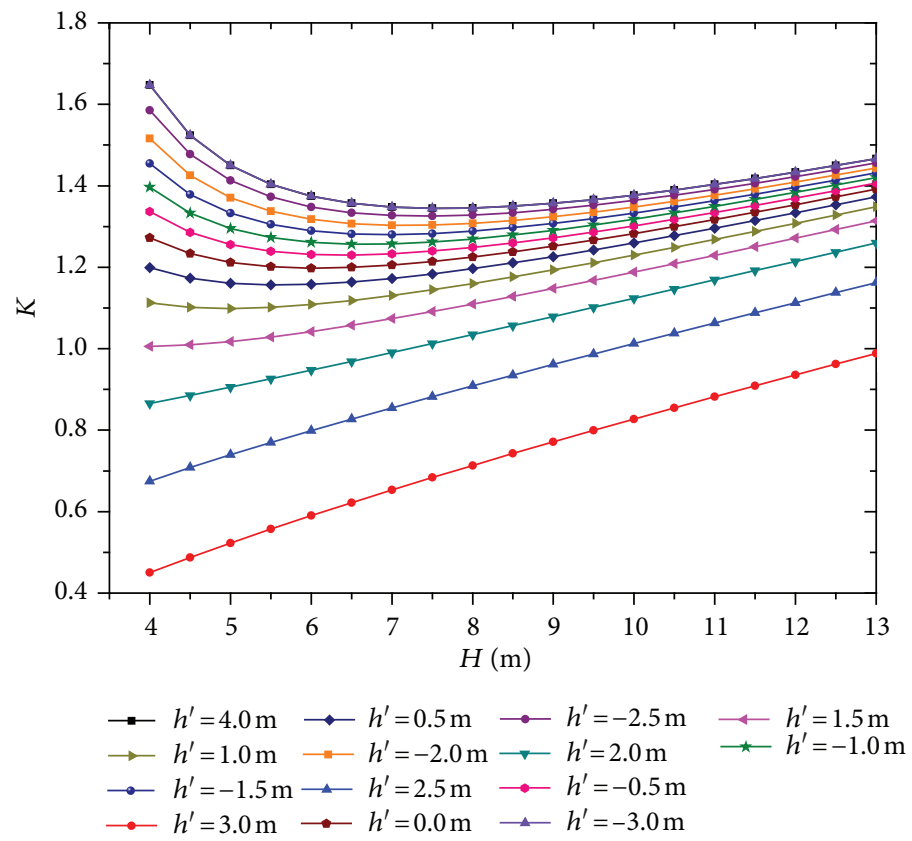

(a)

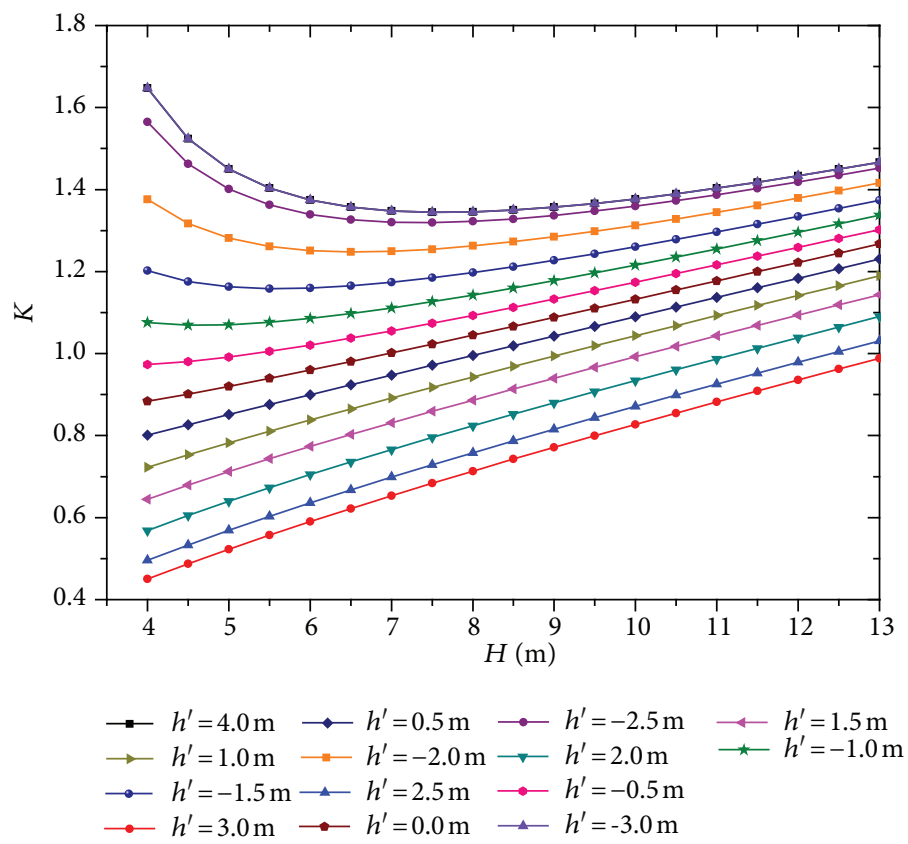

(b)

Figure 5: Continued. 


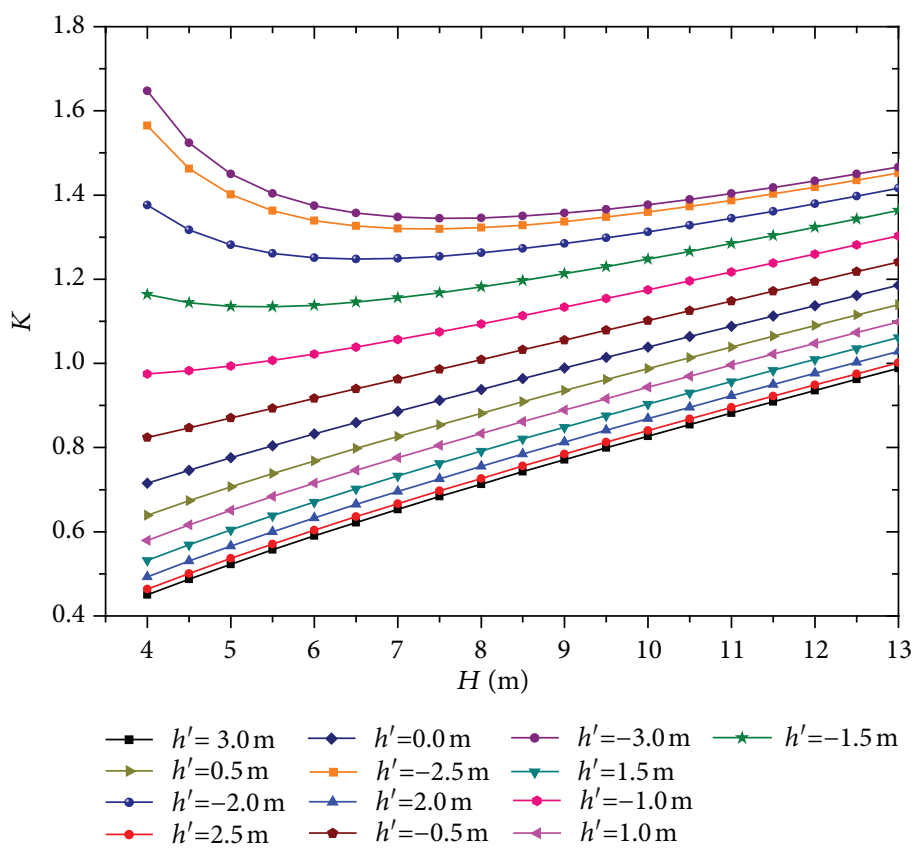

(c)

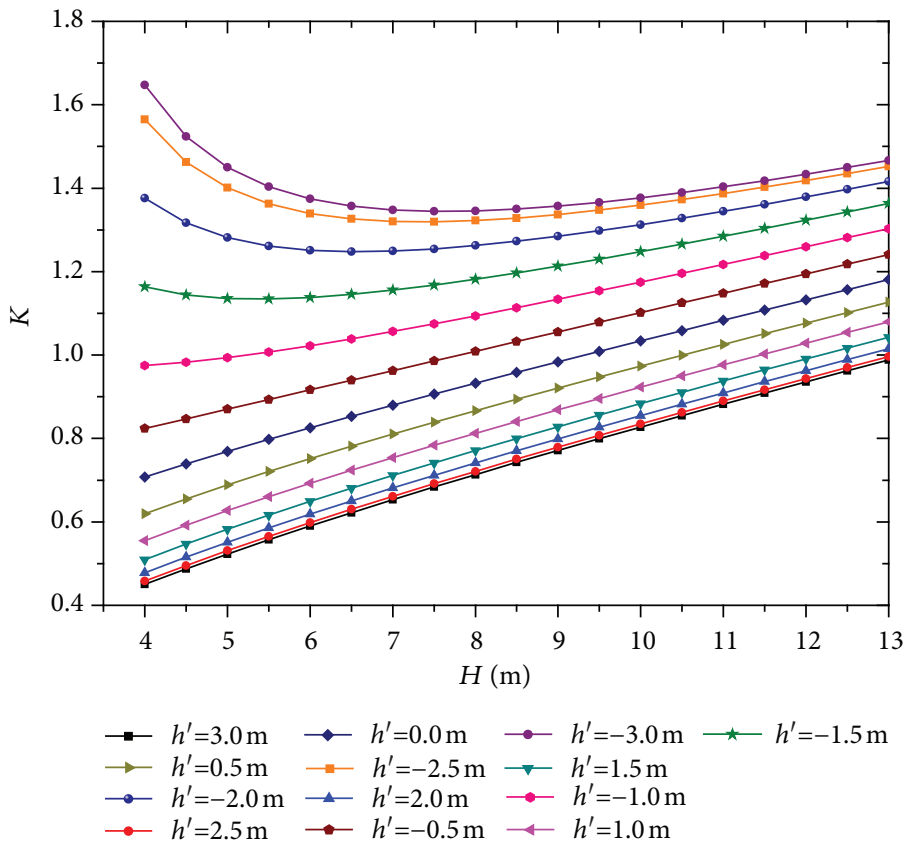

(d)

Figure 5: Influence of overburden thickness under the same drawdown. (a) $\Delta h=0.5 \mathrm{~m}$. (b) $\Delta h=1.0 \mathrm{~m}$. (c) $\Delta h=2.5 \mathrm{~m}$. (d) $\Delta h=4.0 \mathrm{~m}$.

(2) With the increase in $h^{\prime}$, the decreasing part of the curve becomes gentler and finally becomes a straight line gradually. Except for the part where $H$ and $h^{\prime}$ are small, other parts of the curve are linear, and with the increase of groundwater drop, more curves with the low initial groundwater level gradually meets this relationship.
The above analysis indicates that we should pay attention to the initial high groundwater level, especially when the overburden is thin. The lower the initial groundwater level and the thicker the overburden are beneficial to the safety. In addition, this conclusion provides an important reference for predicting the stability coefficient under different overburden thickness. We can predict the stability of 
different overburden thickness when the initial groundwater level is is high, or the overburden thickness is thick, especially when the relative drawdown is large, and this prediction is more referential.

\section{Conclusion}

Through the above research, we obtained the following conclusions:

(1) The study constructed a mechanical model for groundwater subsidence in the ellipsoidal soil cave and deduced the expression of stability coefficient about it. Due to the density of the surface soil in the overburden layer and the rapid decline of groundwater, Boyle-Mariotte's law conditions are basically applicable. Then, the formula of negative pressure in soil cavity is deduced, and the feasibility of the theory is verified.

(2) The influence of groundwater parameters shows that when the initial groundwater level is higher than the top of the hole, the curve of the stability coefficient $K$ and the drawdown $\Delta h$ of the soil hole show a jumping horizontal broken line law. When the groundwater level drops over the arch roof, the soil cave collapse may occur. When the initial groundwater level is in the hole body, $K$ negatively correlates to $\Delta h$, showing a trend of steep at the early stage and gentle at the later stage. The higher the initial groundwater level is, the greater the decrease in $K$ is. When the initial groundwater level is lower than the bottom of the hole, $\Delta h$ hardly affects $K$.

(3) The influence of overburden thickness shows that for the small drawdown, $K$ decreases first and then increases with the increase in overburden thickness $H$. The smaller $H$ results in greater reduction rate. For the moderate and high drawdown, there is a positive correlation between $K$ and $H$. When the initial groundwater level is low, $K$ decreases first and then increases with the thickness of overburden $H$. When the initial groundwater level is medium or high, $K$ positively correlates to $H$.

\section{Data Availability}

The data used to support the findings of this study are available from the corresponding author upon request.

\section{Conflicts of Interest}

The authors declare that there are no conflicts of interest.

\section{Acknowledgments}

This work was supported by the National Natural Science Foundation of China (41967037 and 41762022) and Scientific Research Fund of Hunan Provincial Education Department (20C0497 and 19B125).

\section{References}

[1] R. Brinkmann, Florida Sinkholes: Science and Policy, University Press of Florida, Gainesville, FL, USA, 2013.

[2] R. Brinkmann, M. Parise, and D. Dye, "Sinkhole distribution in a rapidly developing urban environment: hillsborough County, Tampa Bay area, Florida," Engineering Geology, vol. 99, no. 3-4, pp. 169-184, 2008.

[3] H. Xiao, Y. J. Kim, and D. B. W. Boo Hyun Nam, "Investigation of the impacts of local-scale hydrogeologic conditions on sinkhole occurrence in East-Central Florida, USA," Environmental Earth Sciences, vol. 75, p. 1274, 2016.

[4] J. Long and L. J. Li, "Responses of cover-collapse sinkholes to groundwater changes: a case study of early warning of soil cave and sinkhole activity on Datansha Island in Guangzhou, China," Environmental Earth Sciences, vol. 77, p. 488, 2018.

[5] X. Z. Jiang, M. T. Lei, and Y. L. Gao, "Formation mechanism of large sinkhole collapses in Laibin, Guangxi, China," Environmental Earth Sciences, vol. 76, p. 823, 2017.

[6] D. Closson, P. E. LaMoreaux, N. A. Karaki, and H. al-Fugha, "Karst system developed in salt layers of the lisan peninsula, dead sea, Jordan," Environmental Geology, vol. 52, pp. 155$172,2007$.

[7] M. D. Fidelibus, F. Gutiérrez, and G. Spilotro, "Human-induced hydrogeological changes and sinkholes in the coastal gypsum karst of Lesina Marina area (Foggia Province, Italy)," Engineering Geology, vol. 118, no. 1, pp. 1-19, 2011.

[8] F. Gutiérrez, J. P. Galve, P. Lucha, J. Bonachea, L. Jordá, and R. Jordá, "Investigation of a large collapse sinkhole affecting a multi-storey building by means of geophysics and the trenching technique, Zaragoza city, NE Spain," Environmental Geology, vol. 58, pp. 1107-1122, 2009.

[9] L. Pando, J. A. Pulgar, and M. Gutierrez-Claverol, "A case of man-induced ground subsidence and building settlement related to karstified gypsum (Oviedo, NW Spain)," Environmental Earth, vol. 68, pp. 507-519, 2013.

[10] K. Taheri, F. Gutiérrez, M. Hassan, E. Raeisi, and M. Taheri, "Sinkhole susceptibility mapping using the analytical hierarchy process (AHP) and magnitude-frequency relationships: a case study in Hamadan province, Iran," Geomorphology, vol. 234, no. 1, pp. 64-79, 2015.

[11] E. L. Kuniansky, D. J. Weary, and J. E. Kaufmann, "The current status of mapping karst areas and availability of public sinkhole-risk resources in karst terrains of the United States," Hydrogeology Jounal, vol. 24, no. 3, pp. 613-624, 2015.

[12] W. L. Wilson, EJ Shock, "New Sinkhole Data Spreadsheet Manual (v1.1) Subsurface Evaluations, Winter Springs, 1996.

[13] B. Wang, K. Q. He, and Z. J. Gao, "Temporal and spatial stage analysis of Karst collapse development," Hydrogeology \& Engineering Geology, vol. 5, pp. 24-27, 2001.

[14] M. D. Cahalan and A. M. Milewski, "Sinkhole formation mechanisms and geostatistical-based prediction analysis in a mantled karst terrain," Catena, vol. 165, no. 1, pp. 333-344, 2018.

[15] I. Kleinhans and J. L. Van Rooy, "Guidelines for sinkhole and subsidence rehabilitation based on generic geological models of a dolomite environment on the East Rand, South Africa," Jounal of African Earth Sciences, vol. 117, pp. 86-101, 2016.

[16] N. Alfarrah, G. Berhane, A. Hweesh, and K. Walraevens, "Sinkholes due to groundwater withdrawal in Tazerbo 
Wellfield, SE Libya.groundwater," Groundwater, vol. 55, no. 4, pp. 593-601, 2017.

[17] F. W. Jiang, "Discussion of the pipe flow model to analyze the critical parameter of seepage erosion forming sinkholes in Liuzhou, China," Bulletin of Engineering Geology and the Environment, vol. 78, 2018.

[18] F. Gutiérrez, M. Parise, J. De Waele, and H. Jourde, "A review on natural and human-induced geohazards and impacts in karst," Earth-Science Reviews, vol. 138, pp. 61-88, 2014.

[19] M. D. Aurit, R. O. Peterson, and B. Jia, "GIS analysis of the relationship between sinkholes, dry-well complaints and groundwater pumping for frost-freeze protection of winter strawberry," PLoS One, vol. 8, no. 1, 2013.

[20] R. Linares, C. Roqué, F. Gutiérrez et al., "The impact of droughts and climate change on sinkhole occurrence. A case study from the evaporite karst of the Fluvia Valley, NE Spain," The Science of the Total Environment, vol. 579, pp. 345-358, 2017.

[21] A. Youssef, H. M. Al-Harbi, F. Gutiérrez et al., "BA El-Haddad "Natural and human-induced sinkhole hazards in Saudi Arabia: distribution, investigation, causes, and impacts," Hydrogeology Journal, vol. 24, pp. 625-644, 2016.

[22] G. L. Chen, Causes and Prevention of Karst Ground Collapse, China Railway Publishing House, Beijing, China, 1994.

[23] D. Romanova and G. Kaufmann, "Basic processes and factors determining the evolution of collapse sinkholes-a sensitivity study," Engineering Geology, vol. 275, 2020.

[24] B. Wang and K. Q. He, "Study on limit equilibrium height expression of critical soil cave of karst collapse," Rock and Soil Mechanics, vol. 27, no. 3, pp. 458-462, 2006.

[25] D. S. Chang and L. M. Zhang, "Critical hydraulic gradients of internal erosion under complex stress states," Journal of Geotechnical and Geoenvironmental Engineering, vol. 139, no. 9, pp. 1454-1467, 2013.

[26] B. H. Nam, Y. J. Kim, and H. Youn, "Identifification and quantitative analysis of sinkhole contributing factors in Florida's Karst," Engineering Geology, vol. 271, Article ID 105610, 2020.

[27] X. X Xiao, Deformation Behavior Evolution and Collapse Mechanism of Karst Covers under Water-Air Interaction in Karst Area, Chengdu University of Technology, Chengdu, China, 2018.

[28] R. H. Edwards, "Stress concentrations around spheroidal inclusions and cavities," Journal of Applied Mechanics, vol. 73, pp. 19-30, 1951.

[29] L. P. Liao, W. K. Yang, and Q. Z. Wang, "Stability analysis of an ellipsoidal cavity in foundation," Rock and Soil Mechanics, vol. 31, pp. 138-148, 2010.

[30] Q. Q. Li, D. L. Zhang, and Q. Fang, "Analytic solution to initial damage of cavern strata by complex function method," Chinese Journal of Geotechnical Engineering, vol. 36, no. 11, pp. 2110-2117, 2014.

[31] H. Zhao, Y. Xiao, and M. H. Zhao, "Stability assessment method for subgrade with underlying rectangular cavity," China Journal of Highway and Transport, vol. 31, no. 2, pp. 165-180, 2018.

[32] Y. Hu, M. Qi, Y. Peng, Y. Li, and J. Huang, The Geological Hazards Investigation Report in Datansha Island in Guangzhou City, Guangzhou Institute of Geological Survey, Guangzhou, China, pp. 30-33, 2009. 